\title{
PARA UMA HISTÓRIA EPISTEMOLÓGICA DO CONCEITO DE FORMAÇÃO DISCURSIVA*
}

\author{
Claudiana Narzetti ${ }^{*}$ \\ Universidade do Estado do Amazonas \\ Escola Normal Superior \\ Manaus, AM, Brasil
}

\begin{abstract}
Resumo: Este ensaio objetiva retomar algumas questões históricas e epistemológicas relativas ao conceito de formação discursiva elaborado por Michel Pêcheux, no seio da Análise do discurso francesa. É um conceito central da teoria do discurso que, paradoxalmente, tornou-se alvo de mal-entendidos, assimilações apressadas e, mesmo, propostas de abandono. A retomada do tema sustenta-se no pressuposto de que ele não foi exaustivamente explorado nos trabalhos existentes. As questões epistemológicas relacionadas ao conceito são centrais neste ensaio, e buscam esclarecer, sustentadas em dados históricos: o paradigma teórico a partir do qual o conceito foi elaborado; seu núcleo conceitual e permanente; suas transformações (retificações, refinamentos e ampliações); a especificidade do conceito elaborado por Michel Pêcheux e sua demarcação em relação ao conceito homônimo de Michel Foucault. Os argumentos e as conclusões obtidas revelam alguns mal-entendidos que ainda hoje permanecem na história da Análise do discurso francesa.
\end{abstract}

Palavras-chave: Análise do discurso. Formação discursiva. Michel Pêcheux. Epistemologia.

\section{CONSIDERAÇÕES INICIAIS}

Formação discursiva (doravante FD) é um dos principais conceitos da Análise do discurso constituída em torno dos trabalhos de Michel Pêcheux, na França. Isso se deve tanto ao fato de estar relacionado a questões centrais desse campo de investigação quanto ao fato de articular uma série de outros conceitos da teoria (discurso, sentido, interdiscurso, ideologia), formando uma rede conceptual relativamente tenaz.

Previsivelmente, ao longo de sua história, o conceito foi objeto de críticas, revisões, reformulações. Dizemos "previsivelmente", porque sabemos, desde G. Bachelard e G. Canguilhem, que tais transformações são constitutivas do próprio modo de ser de uma ciência.

Dentre os conceitos da teoria do discurso, o de FD foi, sem dúvida, o que mais passou pelo processo acima citado. Os problemas metodológicos relacionados a esse conceito encontrados nos primeiros momentos da análise do discurso, bem como as próprias mudanças na problemática da teoria do discurso suscitaram e possibilitaram

\footnotetext{
* Este trabalho apresenta resultados de um projeto de pesquisa de Produtividade Acadêmica, financiado pela Universidade do Estado do Amazonas.

** Doutora em Linguística e Língua Portuguesa. Professora do Curso de Letras e do Programa de PósGraduação em Letras e Artes (PPGLA) da Universidade do Estado do Amazonas. ORCID: <https://orcid.org/0000-0002-5527-440X>. E-mail: cn.narzetti@gmail.com.
} 
retificações e refinamentos do conceito. Porém, por outro lado, conduziram alguns a propor seu abandono ou mesmo a abandoná-lo efetivamente.

Há diversos trabalhos sobre a história da Análise do discurso francesa; sobre o empreendimento ou o percurso de Pêcheux em particular; e, ainda, sobre o conceito de FD (Cf. sobre esta última questão GUILHAUMOU, 2007; SANTOS, 2015; BARONAS, 2007). Há, também, dicionários e manuais destinados a apresentar e definir aos iniciantes os conceitos da teoria do discurso, dentre os quais figura obrigatoriamente o de FD (Cf., por exemplo, BRANDÃO, 2004). No entanto, sobre FD, parecem faltar trabalhos que façam uma abordagem histórico-epistemológica do conceito, isto é, que reconstruam a síntese conceitual em que ele está inserido; que indiquem os problemas que ele formula, bem como os componentes que definem sua endo-consistência. Essa ausência parece ficar evidente na discussão acerca da "paternidade" do conceito, de onde está frequentemente excluída toda consideração epistemológica, ficando o debate reduzido a uma questão de prioridade cronológica no emprego de uma palavra. A consequência dessa ausência é o emprego amiudado de conceitos homônimos, como se a identidade terminológica significasse identidade conceitual.

O presente ensaio pretende contribuir para o preenchimento de algumas das lacunas acima apontadas, sem objetivar, absolutamente, ser a última palavra acerca da questão. Sua necessidade provém do fato de que a entrada em análise do discurso, por parte de novos pesquisadores, não pode ser prejudicada por esse conjunto de lacunas e malentendidos. Além disso, a análise de discursos diversos não pode prescindir de uma compreensão efetiva dos conceitos da teoria e do método de $\mathrm{AD}$, sob o risco de se tornarem meras interpretações impressionistas dos objetos analisados.

Abordamos neste ensaio o conceito de FD formulado por Pêcheux ao longo de sua trajetória teórica. Neste sentido, apontamos as obras do autor em que tal conceito é apresentado, destacando duas: aquela em que o conceito (ou melhor, o esboço do conceito) é apenas mencionado, e aquela em que ele aparece pela primeira vez definido; explicitamos a problemática à qual esse conceito responde e em qual contexto teórico ele se inscreve; sumarizamos, por um lado, as retificações, refinamentos e ampliações e, por outro, o núcleo que se mantém inalterado ao longo das referidas obras. A exposição será útil a duas finalidades: uma é fazer uma abordagem de natureza histórico-epistemológica da evolução do conceito pecheutiano; outra é elencar elementos de base para uma distinção deste com o conceito foucaultiano de mesmo nome.

\section{PRESSUPOSTOS TEÓRICOS}

Para fazer a história epistemológica do conceito de FD, temos inescapavelmente de recorrer a Georges Canguilhem. Como se sabe, foi ele quem assinalou a importância da análise e crítica dos conceitos para a história de um saber com pretensões científicas.

\footnotetext{
L'histoire des sciences peut sans doute distinguer et admettre plusieurs niveaux d'objets dans le domaine théorique spécifique qu'elle se constitue: documents à cataloguer; instruments et techniques à décrire ; méthodes et questions à interpréter; concepts à analyser et à critiquer. Cette dernière tâche seule confère aux précédentes la dignité d'histoire des sciences. (CANGUILHEM, 2002, p. 19)
} 
Como não há ciência sem conceitos, a história de um dos níveis de objeto só será história das ciências na medida em que estes estiverem relacionados com teorias, isto é, com sistemas de conceitos. A abordagem dos conceitos proposta e realizada por Canguilhem apresenta alguns pressupostos principais, que adotaremos aqui.

O primeiro, obviamente, é a historicidade dos conceitos. Um conceito não existe desde sempre nem permanece imutável; ao contrário, ele é produzido em determinado momento e, ao longo do tempo, passa por reformulações, que o corrigem, o refinam ou o ampliam.

Considerando a importância assinalada aos conceitos no interior de uma ciência e o caráter histórico da existência deles é que Canguilhem condena a redução da história da ciência a uma mera coleção de biografias ou a um quadro cronológico colorido com episódios anedóticos. Ela deve ser, essencialmente, "une histoire de la formation, de la déformation et de la rectification de concepts scientifiques" (CANGUILHEM, 2002, p. 235).

O segundo pressuposto é a distinção entre palavra e conceito: “Un même mot n'est pas un même concept" (CANGUILHEM, 2002, p. 177). Um conceito supõe, além da palavra, uma definição ou, ao menos, um esboço de definição. É esta que permite identificar o conceito. "Ela o especifica entre os conceitos e enquanto conceito" (MACHEREY, 1990, p. 289). Em suma, um conceito só o é na medida em que se encontra relacionado com outros numa síntese conceitual.

A tarefa de quem faz história das ciências será, portanto, a de "reconstituer la synthèse dans laquelle le concept se trouve inséré, c'est-à-dire à la fois le contexte conceptuel et l'intention directrice des expériences ou observations" (CANGUILHEM, 2002, 177). Desse modo,

\footnotetext{
Elle gardera l'historien de la fausse objectivité qui consisterait à dresser l'inventaire de tous les textes dans lesquels à une époque donnée, ou à des époques différentes, apparaît le même mot, dans lesquels les projets de recherches semblables paraissent s'exprimer dans des termes substituables. (CANGUILHEM, 2002, p. 177)
}

O terceiro pressuposto é a relação do conceito com uma problemática. "Definir um conceito é formular um problema" (MACHEREY, 1990, p. 289). Esse pressuposto fica mais bem entendido, se distinguimos o conceito da teoria:

\footnotetext{
Uma teoria é constituída por um feixe de conceitos, ou melhor, por um conjunto coerente de conceitos, por um sistema conceitual. E, neste sistema, enquanto o conceito assinala a existência de uma questão, a formulação de um problema, a teoria apresenta determinada resposta, sugere uma solução. (MACHADO, 1988, p. 24)
}

Como resume Macherey (1990, p. 295): "se o conceito está do lado das questões, a teoria está do lado das respostas. Partir do conceito é escolher partir das questões para se escrever a história".

Além desses três pressupostos sugeridos por Canguilhem, adotaremos ainda um quarto, que foi sugerido por Deleuze e Guattari (1992). O de que não há conceito simples, pois "todo conceito tem componentes, e se define por eles (DELEUZE; GUATTARI, 1992, p. 27). Esclarecem os autores: “[...] é próprio do conceito tornar os componentes 
inseparáveis nele: distintos, heterogêneos e todavia não separáveis, tal é o estatuto dos componentes, ou o que define a consistência do conceito, sua endo-consistência" (DELEUZE; GUATTARI, 1992, p. 31).

Estamos conscientes de que o uso epistemológico que faremos dessa sugestão de Deleuze e Guatarri contraria a intenção de seus propositores, uma vez que eles pensavam o conceito como uma prerrogativa da filosofia (a ciência, segundo eles, lidava com "funções", não com conceitos). Entretanto pensamos que o "conceito de conceito" proposto por eles tem muitos pontos de concordância com o de Canguilhem, o que permite sua incorporação numa abordagem epistemológica.

\section{A EMERGÊNCIA DO CONCEITO}

O conceito de FD formulado por Pêcheux aparece, pela primeira vez, em 1971, em dois trabalhos: a. o artigo "Língua, linguagens, discurso", assinado unicamente por Pêcheux, e publicado no jornal comunista L'Humanité (Cf. PÊCHEUX, 2011); b. o artigo "A semântica e o corte saussuriano: língua, linguagem, discurso", assinado por Michel Pêcheux, Claudine Haroche e Paul Henry, e publicado no número 24 da revista Langages. Nesses dois artigos, o mesmo conceito de FD é apresentado. Voltaremos à definição desse conceito logo a seguir.

Porém, a expressão formação discursiva aparece já em 1970, na obra intitulada Considérations théoriques à propos du traitement formel du langage, assinada por Antoine Culioli, Catherine Fuchs e Michel Pêcheux. A passagem em que Pêcheux cita a referida expressão é uma nota de rodapé, inserida no texto assinado por Culioli ("La formalisation en linguistique"), que constitui a primeira parte do livro: "la langue n'est pas une superstructure (au sens marxiste de ce mot) mais d'avancer que les formations discursives sont, elles, fondamentalement liées aux superstructures, à la fois comme effets et comme causes (PÊCHEUX apud NORMAND, 1972). Aparece nesse texto, como dissemos acima, o esboço do conceito e o termo que o nomeia, e não exatamente o conceito já formulado.

As outras obras nas quais o conceito é retomado a propósito de retificações, ampliações e refinamentos, são: o artigo, escrito com C. Fuchs, "A propósito da Análise automática do discurso: atualizações e perspectivas", publicado na Langages, em 1975; o livro Semântica e discurso, de 1975; o artigo "Remontons de Foucault à Spinoza", de 1977; o artigo "A análise do discurso: três épocas", de 1983.

\section{CONTEXTO CONCEITUAL E O PARADIGMA TERMINOLÓGICO}

No artigo publicado no L'Humanité, Pêcheux anuncia:

\footnotetext{
Apoiando-nos em grande número de observações contidas no que chamamos de "os clássicos do marxismo", nós sustentaremos a ideia de que as formações ideológicas assim definidas comportam necessariamente, como um de seus componentes, uma ou várias formações discursivas interligadas, que determinam o que pode e deve ser dito [...], a partir de uma dada posição numa dada conjuntura [...]. (PÊCHEUX, 2011, p. 73)
} 
No texto de 1971, Pêcheux, Haroche e Henry definem FD fazendo uma referência explícita à teoria das ideologias de Althusser, tal como foi exposta principalmente em Ideologia e aparelhos ideológicos de Estado. Os autores relembram que uma formação social, num dado momento histórico, é caracterizada por um modo de produção dominante e por um Estado determinado pelas relações das classes que o constituem. Este por sua vez, desdobra-se em aparelhos: o aparelho repressivo e os aparelhos ideológicos. Nos aparelhos ideológicos, realizam-se as formações ideológicas (FI), concebidas como um "conjunto complexo de atitudes e de representações que não são nem 'individuais' e nem 'universais', mas que se relacionam mais ou menos diretamente a posições de classes em conflito umas em relação às outras" (HAROCHE; HENRY; PÊCHEUX, 2007, p. 26).

Os autores avançam que essas FIs contêm, como um de seus componentes, FDs, que determinam "o que pode e o que deve ser dito a partir de uma posição dada numa conjuntura dada” (HAROCHE; HENRY; PECCHEUX, 2007, p. 26). Em outras palavras, que dizem respeito à realização material das ideologias na linguagem.

Está claro, portanto, o paradigma teórico em que o conceito de FD é elaborado. Conforme Maldidier (2003, p.52): "No início dos anos 70, para Michel Pêcheux e seus amigos, a palavra 'formação' pertence à terminologia marxista. No paradigma 'formação social', 'formação ideológica'... faltava um elemento: 'formação discursiva"”.

\section{A PROBLEMÁTICA NA QUAL SE INSERE O CONCEITO PECHEUTIANO DE FD}

Conforme dissemos acima, do ponto de vista de Canguilhem, definir um conceito é formular uma problemática. $\mathrm{O}$ conceito pecheutiano de FD não escapa a essa regra.

O primeiro problema visado no projeto pecheutiano é a busca de uma teorização das ideologias concretas no seio de uma sociedade em dado momento histórico. A reflexão de Michel Pêcheux em seus primeiros trabalhos (dois artigos publicados com o pseudônimo de Thomas Herbert) centra-se na tentativa de elaboração de uma teoria geral das ideologias, em consonância com o projeto teórico de seu mestre Louis Althusser. Mas, logo em seguida, seus esforços se direcionam à teorização sobre as ideologias concretas, tal como elas aparecem nas sociedades de classes, isto é, divididas em regiões e apresentando uma tendência de classe. Nesse sentido, o primeiro problema que o conceito de FD formula é: como pensar a articulação entre "regiões ideológicas" e tendências de classe?

O segundo problema é o da relação entre sentido e ideologia. Em "A semântica e o corte saussuriano...", Haroche, Henry e Pêcheux (2007) destacam que as FD não apenas materializam na linguagem as ideologias, mas também são o lugar de constituição do sentido das palavras e expressões "da língua".

Sustentam os autores que o corte epistemológico operado por Saussure não foi suficiente para fundar a semântica sobre princípios científicos. $\mathrm{O}$ estudo do sentido exigiria, pela sua natureza mesma, uma mudança de terreno, isto é, ser deslocado da linguística para outro campo teórico, o de uma semântica discursiva. 
Em seu princípio, essa mudança de terreno [acerca do estudo do sentido] consiste em se desembaraçar da problemática subjetivista centrada no indivíduo, fonte dos gestos e das falas, ponto de vista sobre os objetos e sobre o mundo, e em compreender que o tipo de concreto com o qual lidamos e sobre o qual pensamos é precisamente o que o materialismo histórico designa pelo termo de relações sociais, que resultam de relações de classe característica de uma dada formação social [...]. (PÊCHEUX, 2011, p. 71-72)

O que tornaria essa mudança de terreno necessária? Dissemos anteriormente que é a natureza do sentido que o exige. Na passagem acima citada, Pêcheux esclarece que o sentido de uma palavra ou expressão é determinado pelas posições de classe daquele que emprega essa palavra ou expressão. Isto é, o sentido não é exclusivamente linguístico, mas sócio-histórico (o que quer dizer, afetado pelas classes e os antagonismos e interesses de classes; afetado pelas posições de classes constituintes das ideologias). Palavras, expressões e enunciados possuem um caráter material que é, entretanto, dissimulado pela ilusão, que afeta os sujeitos, da transparência da linguagem, segundo a qual os sujeitos sabem o que é uma greve, uma guerra, uma democracia...

A tese do caráter material das palavras e expressões significa que, uma vez que as FDs são elementos das formações ideológicas e, portanto, são atravessadas por tendências de classe, estas últimas estão diretamente relacionadas com um fato que contraria radicalmente a ilusão da transparência, da evidência e da universalidade das palavras: o fato de que a divisão da sociedade em classes afeta a linguagem, o sentido; determina que o sentido varie (o que, no fim das contas, desfaz a ilusão da evidência e da neutralidade do sentido). Assim, é no interior das formações discursivas que o sentido se constitui; que um sentido é atribuído a uma palavra. ${ }^{1}$

Na obra Semântica e discurso, Pêcheux (1988) destaca que a FD é a matriz do sentido das palavras e expressões e que, consequentemente, estas ganham um sentido na medida em que pertencem a uma FD.

Dessa maneira, no empreendimento pecheutiano, o conceito de FD, criado sob o paradigma da teoria marxista (formação social, formação ideológica e formação discursiva), insere-se em uma determinada problemática: a da mudança ou variação do sentido das palavras e das expressões em sua íntima relação com a existência de uma sociedade dividida em classes.

Trata-se, deve-se ter isso bem claro, de uma problemática pautada pela perspectiva marxista em que o sentido é definido por sua natureza sócio-histórica, isto é, resultando de ou sendo determinado por fatores sociais, notadamente as relações sociais.

\section{RETIFICAÇÕES, REFINAMENTOS, AMPLIAÇÕES DO CONCEITO DE FD}

Ao longo de sua história, o conceito de FD tal como proposto por Pêcheux, sofreu "modificações" de diversos tipos: retificações, refinamentos, ampliações. Mas também manteve o núcleo conceptual existente desde o momento de sua formulação, sem o qual deixaria de existir e daria lugar a outro conceito. Muito se fala das retificações (ainda que pouco se elucide a respeito delas, pouco se aponte o que foi efetivamente retificado), mas pouco se fala sobre os refinamentos e as ampliações do conceito.

\footnotetext{
1 Para Pêcheux, o sentido não é um a priori, mas um efeito.
} 
A ampliação do conceito se dá quando Pêcheux relaciona a FD não somente à constituição do sentido, mas também à interpelação dos indivíduos em sujeitos e à constituição do sujeito do discurso, a partir de uma articulação com o conceito althusseriano de Aparelhos ideológicos de Estado. A retificação e o refinamento, por sua vez, fazem-se simultaneamente, quando Pêcheux propõe que, na verdade, a FD não seria homogênea, mas heterogênea.

A fim de tratarmos das referidas transformações do conceito de FD, iniciaremos sintetizando a primeira definição dada a ele por Pêcheux e seu grupo.

É em 1971, no artigo "Língua, linguagens, discurso", que Pêcheux apresenta, pela primeira vez, o conceito de FD, definindo-o a partir de dois outros conceitos, formação ideológica e sentido, isto é, desde uma articulação entre o Marxismo e a Linguística. Mas essa mesma definição é retomada (e pormenorizada) em obras posteriores: o artigo "A semântica e o corte saussuriano: língua, linguagem, discurso" (escrito juntamente com Claudine Haroche e Paul Henry), de 1971; o artigo "A propósito da Análise Automática do Discurso: atualizações e perspectivas" (escrito juntamente com Catherine Fuchs), de 1975; e, finalmente, em Semântica e discurso, de 1975. Em suma: nas referidas obras, é permanente essa definição.

\footnotetext{
Apoiando-nos em grande número de observações contidas no que chamamos de "os clássicos do marxismo", nós sustentaremos a ideia de que as formações ideológicas assim definidas comportam necessariamente, como um de seus componentes, uma ou várias formações discursivas interligadas, que determinam o que pode e deve ser dito [...], a partir de uma dada posição numa dada conjuntura [...]. (PÊCHEUX, 2011, p.73)
}

Vamos à discussão do primeiro aspecto definidor de FD: ser um dos componentes das formações ideológicas, componente esse relativo a um dos aspectos materiais da ideologia, qual seja, o aspecto linguístico/discursivo.

Enquanto componente da FI, a FD possui um aspecto regional (assim como toda FI) e é atravessada por uma tendência de classe (assim como toda FI): "a instância ideológica existe sob a forma de formações ideológicas [...], que, ao mesmo tempo, possuem um caráter 'regional' e comportam posições de classe” (PÊCHEUX, 1985, p. 146).

O aspecto regional é o que permite que uma FD fale de "temas" que lhe são "próprios" ou, melhor dizendo, que definem, de certa maneira, suas fronteiras em relação a outras FD (Deus, a liberdade, a razão, a moral, a democracia). A tendência de classe que atravessa uma FD é o que faz com que ela fale desse "tema" a partir da perspectiva de determinada classe social. Em outras palavras, uma FD se caracteriza por falar de um "tema" (aspecto regional), mas esse "tema" é concebido e abordado aí de uma maneira específica, própria a ela: a submissão dos servos aos nobres/a submissão dos nobres a Deus (Cf. PÊCHEUX; FUCHS, 1997).

Essa abordagem do "tema" de maneiras diferentes acontece por duas razões. A primeira é que as diferentes classes que compõem uma sociedade ocupam lugares distintos no interior dela e é a partir desse lugar que constituem suas representações sobre as "coisas", que recebem representações diferentes por terem sido elaboradas a partir daquele lugar específico e sofrendo, portanto, as limitações impostas por ele. A segunda 
razão é que as diferentes classes possuem interesses diferentes, comumente contraditórios, no interior dessa mesma sociedade, o que está na base da diferenciação no tratamento de um mesmo "tema" por uma FD.

O segundo aspecto definidor do conceito de FD que perpassa todas as obras de Pêcheux da primeira metade da década de 1970 é o fato de ser a matriz do sentido das palavras e expressões. O problema aqui visado é o da variação do sentido das palavras (isto é, da não existência de um sentido único), e das causas dessa variação. Conforme Haroche, Henry, Pêcheux (2007, p. 26): “[...] as palavras mudam de sentido segundo as posições ocupadas por aqueles que as empregam. [...] as palavras 'mudam de sentido' ao passar de uma formação discursiva a outra".

Pêcheux propõe então que o sentido das palavras se constitui no interior de uma FD e de cada FD. O sentido de uma mesma palavra será um se relacionado a uma FD e será outro se relacionado a outra FD. Isso acontece porque FDs distintas podem falar das mesmas coisas (a beleza), mas a partir de uma perspectiva regional determinada (a beleza na arte, a beleza na filosofia...). E, ainda, porque, conforme a tendência de classe que domina certa FD, o sentido atribuído a uma palavra será específico, pois está relacionado a uma perspectiva e a um interesse de classe também específicos.

A FD funciona por meio de processos parafrásticos e metafórico-metonímicos, sendo ambos interligados. O processo metafórico-metonímico consiste na substituição de uma palavra por outra, determinando que essas palavras, diferentes, recebam o mesmo sentido, tornem-se sinônimas. Esse processo afeta as palavras ou expressões de um enunciado. Conforme Pêcheux (1988, p. 263), “o sentido existe exclusivamente nas relações de metáfora (realizadas em efeitos de substituição, paráfrases, formações de sinônimos), das quais certa formação discursiva vem a ser historicamente o lugar mais ou menos provisório". O processo parafrástico, por sua vez, consiste na substituição de sintagmas de um enunciado e/ou na mudança de sua estrutura sintática. Esse processo afeta o enunciado (difere, portanto, do processo metafórico por não ser exatamente a substituição de uma palavra por outra, ainda que possa ser realizado desta maneira). Na FD, "a produção de sentido é estritamente indissociável da relação de paráfrase entre sequências tais que a família parafrástica destas sequências constitui o que se poderia chamar a "matriz do sentido"” (PÊCHEUX; FUCHS, 1997, p. 169). A análise de uma FD visa, assim, a descrever os processos discursivos, isto é, "o sistema de relações de substituição, paráfrases, sinonímias, etc., que funcionam entre elementos linguísticos 'significantes' - em uma formação discursiva dada" (PÊCHEUX, 1985, p. 161).

Nota-se aqui uma explicação sócio-histórica para o sentido, que supera as teorias semânticas de base linguística, objeto da crítica de Haroche, Henry e Pêcheux no artigo de 1971. O sentido, enquanto apenas parcialmente linguístico e majoritariamente histórico, só poderia ser objeto de uma semântica discursiva a ser construída fora do terreno da linguística stricto sensu.

\footnotetext{
Em seu princípio, essa mudança de terreno [acerca do estudo do sentido] consiste em se desembaraçar da problemática subjetivista centrada no indivíduo, fonte dos gestos e das falas, ponto de vista sobre os objetos e sobre o mundo, e em compreender que o tipo de concreto com o qual lidamos e sobre o qual pensamos é precisamente o que o materialismo histórico designa pelo termo de relações sociais, que resultam de relações de classe característica de uma dada formação social [...]. (PÊCHEUX, 2011, p. 71-72)
} 
Nas quatro obras acima citadas, Pêcheux define o conceito de FD. Pode-se afirmar que nelas há uma mesma definição que permanece, com alguma pormenorização no artigo de 1975. Mas, nesse mesmo artigo e no livro Semântica e discurso, Pêcheux opera uma ampliação do referido conceito. Essa ampliação refere-se à articulação da FD com os conceitos althusserianos de interpelação e assujeitamento, visando a uma explicação do modo de constituição do sujeito do discurso e da ilusão subjetiva atrelada à ilusão da transparência do sentido.

Retomando as formulações de Althusser, Pêcheux lembra que, de maneira geral, a ideologia interpela os indivíduos em sujeitos, isto é, constitui os sujeitos. De maneira mais específica, uma formação ideológica determinada, em dado momento histórico, interpela os indivíduos em sujeitos em nome de um Sujeito com o qual se identificam. O exemplo é o da FI religiosa, dominante no regime de produção feudal: a FI religiosa interpela os indivíduos em sujeitos religiosos em nome de Deus, com que são levados a se identificar; essa identificação dos sujeitos com o Sujeito relaciona-se à identificação dos sujeitos entre si, permitindo que sejam "solidários" e figurativizem as relações econômicas e jurídicas nessas relações religiosas dos homens com Deus.

A tese de Althusser é que os sujeitos não são a causa de si; ou, ainda, que os sujeitos são antes o resultado de um processo dirigido por instâncias que lhe ultrapassam: a ideologia, o inconsciente e a língua. O sujeito é resultado de um processo, é assujeitado. Desde que se torna sujeito, o indivíduo está "apto" a se inserir nas mais diversas práticas sociais, tais como o trabalho, a militância, o esporte, dentre outras.

Pêcheux, por seu turno, propõe uma explicação para a constituição do sujeito do discurso. Avança o autor que “os indivíduos são 'interpelados' em sujeitos-falantes (sujeitos de seu discurso) pelas formações discursivas que representam 'na linguagem' as formações ideológicas que lhes são correspondentes” (PÊCHEUX, 1988, p. 161). Em outras palavras, a interpelação do indivíduo em sujeito de seu discurso se efetua pela identificação (do sujeito) com a FD que o domina (isto é, na qual ele é constituído como sujeito). Então, um sujeito só pode produzir um discurso quando se identifica com dada FD.

No entanto, os sujeitos do discurso funcionam sobre a base da ilusão de que são a fonte do que dizem. Essa ilusão estaria ligada ao fato de que o sujeito é afetado por um duplo esquecimento (que, na verdade, é um desconhecimento) - o sujeito acredita ser a fonte do que diz, porque não sabe que: a) o que diz já foi dito antes; b) o que diz só faz sentido porque está em relação de paráfrase com um já dito antes e em outro lugar.

Trata-se, portanto, de uma ampliação do conceito de FD, que agora é articulado ao processo de constituição do sujeito do discurso. Aqui permanece, entretanto, o núcleo conceitual da FD como elemento da FI e como matriz do sentido e do discurso.

É por meio do conceito de FD e, portanto, da explicação do processo de atribuição de sentido às palavras, que Pêcheux explica como os sujeitos falantes acreditam na transparência do sentido. Ao falarem a partir de uma FD, os sujeitos acreditam na transparência e na unicidade do sentido do que dizem, uma vez que desconhecem o fato de as palavras terem sentido variável. 
Ainda nos trabalhos de 1975, Pêcheux começa um refinamento do conceito de FD, que está ligada, consubstancialmente, a uma retificação. Esse refinamento é anunciado na seguinte tese: "Toda formação discursiva dissimula, pela transparência do sentido que nela se constitui, sua dependência com respeito ao 'todo complexo com dominante' das formações discursivas, intrincado no complexo das formações ideológicas[...]" (PÊCHEUX, 1988, p. 162). O referido "todo complexo com dominante das formações discursivas" é nomeado pelo autor de "interdiscurso".

Vejamos em que consiste esse refinamento do conceito de FD. Na passagem acima, nota-se que Pêcheux insere no conceito dois aspectos não formulados nas reflexões anteriores: o fato de que uma FD depende de outras FD e o fato de que o conjunto das FD forma um todo complexo com dominante. O conjunto das FD existentes em uma sociedade, em dado momento histórico (o "interdiscurso"), não se caracteriza como uma mera somatória de FDs, em que elas estariam justapostas umas às outras, mas ganha a forma de um conjunto complexo, no qual as FDs entretêm relações de aliança, dominação e subordinação. No interior do todo complexo, há uma FD dominante e há FDs subordinadas; cada uma delas estabelece, por sua vez, relações de alianças, confronto, contradição com outras FDs, e assim sucessivamente. ${ }^{2}$ Essas relações se inscrevem na própria materialidade linguística das FDs.

Disso resulta que as FDs não se constituem independentemente umas das outras, mas por um complexo jogo de interconstituição e interdeterminação. Frequentemente, uma FD funciona como matéria-prima para outra: elementos de uma são integrados em outra. Além disso, a própria atribuição de sentido a palavras e expressões no interior de uma FD se dá no interior do interdiscurso, em função dos sentidos de outras FDs.

Anos mais tarde, Jean-Jacques Courtine, no trabalho sobre o discurso comunista dirigido aos cristãos ( $C f$. COURTINE, 2009), demonstrou como a FD comunista da política da mão estendida é uma FD subordinada à FD católica: os temas do discurso da primeira e as próprias construções (estruturas sintáticas) dessa FD são fornecidos e/ou determinados pela FD católica. O trabalho do analista demonstrou a determinação estrutural de uma FD por outra e, portanto, sua interdependência.

Esse refinamento acarreta uma retificação ${ }^{3}$ do conceito de FD: ela passa a ser concebida como heterogênea/aberta ao invés de homogênea/fechada. Na perspectiva da homogeneidade, que marcou os primeiros anos da AD francesa, concebia-se uma FD como homogênea e fechada. Nesse sentido, os discursos eram analisados como se fossem constituídos independentemente de outros discursos, e fechados em si mesmos. As análises se centravam nas diferenças entre FD ou discursos, diferenças essas de sentido, de vocabulário e de usos de estruturas morfossintáticas. Concebiam-se as FDs como unidades justapostas. Essa concepção se fez presente, por exemplo, na análise de JeanBaptiste Marcellesi sobre os discursos do partido comunista e do partido socialista franceses (Cf. MARCELLESI, 1976), e na análise de Bernard Gardin sobre os discursos de operários e de patrões sobre a greve (Cf. GARDIN, 1976).

\footnotetext{
${ }^{2}$ A concepção do conjunto das FDs como um conjunto complexo é uma transposição da própria concepção de Althusser sobre o conjunto dos Aparelhos ideológicos de Estado. Conforme o filósofo, os AIEs não são uma mera lista, mas formam um todo complexo, em que há relações de aliança, subordinação e dominação. ${ }^{3}$ Essa retificação só será apresentada como tal no artigo "Análise do discurso: três épocas", escrito por Pêcheux em 1983 (Cf. PÊCHEUX, 1997).
} 
Na perspectiva da heterogeneidade, elaborada a partir da segunda metade da década de 1970, contrariamente, concebem-se as FDs e os discursos como heterogêneos constitutivamente, isto é, como contendo em seu interior elementos de outros discursos, anteriores e exteriores. Conforme Pêcheux (1997, p. 314):

[...] uma FD não é um espaço estrutural fechado, pois é constitutivamente invadida por elementos que vêm de outro lugar (isto é, de outras FD), que se repetem nela, fornecendolhe suas evidências discursivas fundamentais (por exemplo, sob a forma de 'pré-construídos' e de 'discursos transversos').

\section{Conforme Courtine (2009, p. 235-6), a FD:}

[...] deixa de ser um bloco homogêneo, separada de outras FD por uma fronteira topográfica, como se apenas mantivesse com essas últimas uma relação de distância ou proximidade; resulta enfim a necessidade de deixar de pensar uma FD como repetição na categoria do mesmo (ou do diferente) e de colocar em evidência todas as formas de alteridade constitutivas de sua existência.

Nesse sentido, propõe o analista que as FDs possuem fronteiras flexíveis, que se deslocam em função dos interesses da luta ideológica. As análises passam a descrever as relações entre as FDs no interior do interdiscurso.

$\mathrm{O}$ advento da perspectiva da heterogeneidade na $\mathrm{AD}$ francesa é um dos marcos de sua história, pois define um antes e um depois, isto é, um ponto de não-retorno. A construção dessa perspectiva é resultado de diversos trabalhos, dentre os quais destacamse os de Courtine, a partir da releitura de Foucault, e Jacqueline Authier-Revuz, a partir da releitura de Bakhtin; mas é inaugurada nos trabalhos do próprio Pêcheux, notadamente a partir dos conceitos de interdiscurso, pré-construído e discurso transverso (PÊCHEUX, 1988).

Em 1983, Pêcheux, mencionando as mudanças que afetaram o conceito de FD, afirma que, na segunda época da $\mathrm{AD}$, simultaneamente, avançou-se uma perspectiva da FD que tendia a concebê-la como instável e dividida. Essa perspectiva derivava do fato da descoberta, nos trabalhos então realizados, de sequências discursivas cuja configuração linguística não permitia que o analista identificasse, de modo inequívoco, qual FD havia engendrado a sequência. Segundo Pêcheux (1997, p. 315), "aparece a ideia de uma espécie de "vacilação discursiva" que afeta dentro de uma FD as sequências situadas em suas fronteiras, até o ponto em que se torna impossível determinar por qual FD elas são engendradas". Conclui-se, assim, que toda FD seria passível de conter enunciados divididos, isto é, situados nas fronteiras entre as FDs.

Essa concepção de FD como instável e dividida veio a se coadunar com a concepção da FD como estruturalmente heterogênea. Nesse sentido, acentuou-se o primado do Outro sobre o Mesmo nas análises e nas elaborações teóricas.

No artigo "Remontons de Foucault à Spinoza", de 1977, Pêcheux (1990) destaca um aspecto da definição do conceito de FD que ainda não havia sido significativamente explorado: o aspecto da contradição.

L'axiome d'identité ne s'applique pas à l'objet idéologie [...] une idéologie est non identique à soi-même, elle n'existe que sous la modalité de la division, elle ne se réalise que dans la contradiction qui organise en elle l'unité et la lutte des contraires. (PÊCHEUX, 1990, p. 255) 
Nesse sentido, não apenas as formações ideológicas, mas também as FDs (já que são um dos seus componentes) são afetadas pela contradição. Pêcheux defende, portanto, que na análise das FDs e dos discursos, a abordagem da contradição seja colocada em primeiro plano em relação a uma abordagem meramente tipológica ${ }^{4}$ ou contrastiva.

Essa nova orientação poderia representar naquele momento um redirecionamento teórico e metodológico para o conceito de FD:

Dans ces condition, il apparaît que c'est dans la modalité par laquelle se désignent [...] ces "choses" à la fois identiques e divisées, que se spécifie ce qu'on peut sans inconvénient continuer d'appeler "formation discursive", à la condition toutefois de bien entendre que la perspective régionale [...] se trouve ainsi réordonnée à l'analyse des contradiction de classes. (PÊCHEUX, 1990, p. 258)

O aspecto da contradição poderia ser abordado tanto entre FDs distintas quanto no interior mesmo de uma FD tomada em si mesma. Se as palavras de Pêcheux remetem mais para uma abordagem da contradição no interior mesmo de uma FD, a proposta de Courtine caracterizou-se como abordagem entre FDs distintas: "é a contradição desigual entre formações discursivas antagonistas que é o objeto desse estudo" (COURTINE, 2009, p. 36).

O aspecto da contradição está intimamente ligado à perspectiva da heterogeneidade: "Essa heterogeneidade discursiva, feita de trechos e fragmentos, interessa na medida em que nela podem ser determinadas as condições concretas de existência das contradições pelas quais a história se produz, sob a repetição das "memórias estratégicas"” (PÊCHEUX, 2009, p. 25).

Pêcheux propõe, nesse momento, o primado teórico e metodológico da contradição na abordagem das FDs. Vê-se aqui uma ratificação da perspectiva marxista como uma das bases da definição do conceito de FD, no momento em que os analistas do discurso, pendendo para uma inspiração em Foucault, corriam o risco de apagar em suas análises a questão da contradição.

Enfim, fizemos acima uma sintética reconstrução da evolução do conceito de FD, tal como proposto por Pêcheux. Ao lado das ampliações e das retificações, manteve-se um núcleo conceitual que, de nosso ponto de vista, é a marca da especificidade e da singularidade da análise do discurso proposta por Pêcheux frente a outras propostas paralelas.

\section{A QUESTÃO DA PATERNIDADE DO CONCEITO DE FD}

Uma das questões relacionadas à história do conceito de FD é a da sua "paternidade". Essa questão relaciona-se ao fato de que tanto nas obras de Michel Pêcheux quanto nas de Michel Foucault (notadamente, a Arqueologia do saber) aparece o conceito de formação discursiva.

\footnotetext{
${ }^{4}$ Já no artigo "A propósito da Análise automática do discurso: atualizações e perspectivas”, de 1975, Pêcheux alertava para a dificuldade de discretizar as realidades designadas pelo conceito de FD, destacando que possuem uma natureza dialética: desde aí já era proposto o enfoque nas relações entre FD em detrimento de tipologias (Cf. PÊCHEUX; FUCHS, 1997).
} 
Há, em torno disso, uma celeuma: parte dos analistas do discurso atribui a formulação desse conceito a Foucault e outra defende a tese de uma "dupla paternidade" do conceito pelos dois filósofos. O primeiro grupo sustenta duas posições: a. que Pêcheux fez uma releitura do conceito foucaultiano, articulando-o ao referencial teórico marxista (MAINGUENEAU; CHARAUDEAU, 2004; BARONAS, 2007); b. que Pêcheux operou uma transposição do conceito foucaultiano para a AD (SANTOS, 2015, p. 19). Já o segundo grupo sustenta que os dois autores produziram o conceito (BARONAS, 2007), apesar de assumir que Pêcheux acabou por, posteriormente, fazer uma reelaboração do conceito de Foucault, aproximando-se, assim, paradoxalmente, da posição do primeiro grupo.

Visitando os trabalhos dos autores acima citados, descobrem-se dois critérios comumente utilizados para justificar os posicionamentos: o primeiro é o cronológico e o segundo é o "testemunhal". Pelo critério cronológico, afirma-se que o conceito de FD deriva de Foucault, pois este filósofo já o empregava desde o artigo "Sobre a arqueologia das ciências. Resposta ao círculo epistemológico", de 1968, e da obra Arqueologia do saber, de 1969, enquanto Pêcheux só emprega o conceito a partir de 1970 e 1971 (conforme comentamos acima).

Pelo critério testemunhal/hermenêutico, seguidamente defende-se que, em vários de seus trabalhos, Pêcheux teria assumido que havia se apropriado do conceito de FD elaborado por Foucault: conforme Baronas (2007, p. 175), no artigo "Remontons de Foucault à Spinoza", "Pêcheux explicita a retomada e reelaboração que faz do conceito de formação discursiva de Michel Foucault".

Nossa perspectiva aqui é um tanto diversa. De nosso ponto de vista, trata-se de dois conceitos diferentes, com uma coincidência de termos que o designam. Trata-se de um caso de homonímia, e não de polissemia ou, muito menos, de sinonímia. Cada autor elaborou seu próprio conceito, no interior de uma rede conceitual específica e para responder a uma problemática específica ${ }^{5}$. Pêcheux, portanto, não fez nem uma transposição nem uma releitura do conceito foucaultiano de FD. Ele elaborou seu próprio conceito de FD, paralelamente ao outro.

A exposição que fizemos acima foi destinada exatamente a demonstrar que o conceito de FD formulado por Pêcheux possui uma problemática específica (diferente daquela de Foucault) e insere-se em uma rede conceitual também específica (portanto, muito diversa daquela de Foucault) - formação social, formação ideológica, sujeito, sujeito do discurso, sentido, heterogeneidade, contradição.

Outra forma de mostrar que temos dois conceitos de FD distintos é considerar seus componentes internos. O conceito de Foucault tem como componentes internos quatro tipos de regras de formação de um saber: as dos seus objetos, as das modalidades enunciativas, as dos seus conceitos e as de suas estratégias teóricas. São esses componentes que definem aquilo que Deleuze chama a sua "endo-consistência" enquanto conceito. Foucault os formula tendo sempre por norte fazer uma história dos saberes, contornando dois problemas que ele recusa: o da ideologia e o do sentido. Pêcheux, por sua vez, formula um conceito de FD, em que as regras de formação propostas por Foucault

\footnotetext{
${ }^{5}$ Certamente há proximidades entre esses conceitos, o que permitiu que, na história da $\mathrm{AD}$, fossem realizadas articulações entre ambos, como por exemplo, a proposta de Courtine (2009). A existência de proximidades, entretanto, não anula a existência de diferenças significativas.
} 
não são consideradas e que tem como componentes internos justamente aquilo que Foucault rejeita: o problema da relação entre sentido e ideologia, conforme já mostramos mais acima.

Trata-se, portanto, para nós, de empregar um novo critério, o critério epistemológico, para compreender de outra forma a história do conceito de FD, incluindo aí a questão da sua "paternidade". Diante do critério epistemológico, podem-se fazer duas críticas aos critérios cronológico e testemunhal antes mencionados. O critério cronológico é carente de valor epistemológico, portanto o descartamos de saída. O critério "testemunhal" tem valor elucidativo da questão, mas é perigoso, porque passível de interpretações equivocadas. Portanto, pode ser usado a serviço do critério epistemológico. Vejamos os equívocos derivados desse critério.

O primeiro é não atentar para as exatas palavras do autor no momento mesmo em que se recorre a elas. No artigo já mencionado "Remontons de Foucault à Spinoza", Pêcheux (1990, p. 255) afirma a respeito da FD: "ce term, emprunté à Foucault, peut me semble-t-il rendre de grandes services, mais à la condition expresse de mesurer d'abord ce qui, chez Foucault, en gouverne l'usage, pour tenter de le rectifier" (grifo nosso). Fica bem claro que Pêcheux assume ter tomado de empréstimo de Foucault o termo "formação discursiva" e não o conceito. São duas coisas bem distintas (conceito e termo que nomeia o conceito; ou palavra e conceito, na distinção proposta por Canguilhem que comentamos no início deste trabalho). Pêcheux, como leitor atento de Canguilhem e Bachelard, jamais identificaria palavra e conceito.

O segundo equívoco é não se considerar as efetivas condições de produção dos discursos (um dos principais pressupostos da AD). Nestas condições de produção, os destinatários do discurso são um elemento determinante do que é dito. Faremos isso em relação ao referido artigo de 1977.

Conforme Maldidier (2003), trata-se de uma fala de Pêcheux em um colóquio sobre análise do discurso político realizado no México, no qual se encontravam vários analistas do discurso, de diversas tendências de AD existentes na França. Conforme exposto em trabalhos anteriores (NARZETTI, 2010; 2012), havia uma heterogeneidade interna na análise do discurso francesa, constituindo tendências de $\mathrm{AD}$ ou projetos distintos de análise do discurso.

Em sua fala, Pêcheux critica os trabalhos que faziam uma análise contrastiva dos discursos e dos grupos sociais, sustentando que eles pressupunham uma concepção psicossociológica da sociedade, da qual o aspecto da primazia da contradição sobre os contrários estaria ausente. Trata-se de um momento em que Pêcheux destaca o papel político do analista do discurso, isto é, seu papel nas lutas pela transformação social.

Mas a crítica de Pêcheux dirige-se também aos analistas do discurso que propunham em seus trabalhos uma apropriação dos conceitos da Arqueologia do saber, notadamente o conceito de FD ali elaborado. O motivo é o mesmo: o fato de que a perspectiva foucaultiana não implicava a luta de classes, a contradição e a ideologia.

[...] l'absence de la catégorie de contradiction chez Foucault se paye par le retour de notions comme celes de statut, norme, institution, stratégie, puvoir, etc., qui contournent indéfiniment la question du pouvoir d'État comme enjeu de la lutte de classes, ainsi que le fait tout la psycho-sociologie anglo-saxonne dont ces notion sont d'ailleurs largement issues. (PÊCHEUX, 1990, p. 256) 
Pêcheux não está aqui anunciando o modo como está fazendo uma reelaboração do conceito de Foucault para articulá-lo a sua perspectiva marxista, mas está alertando àqueles que desejam empregar os conceitos de Foucault para os problemas teóricos e políticos que isso poderia acarretar. Na verdade, Pêcheux está insistindo na concepção de FD que ele propunha desde 1971, sendo refinada em 1975 e nesse mesmo texto de 1977 - dando ênfase à contradição entre FDs e entre discursos, como derivadas da contradição social. Seria sem sentido que todo o início do artigo do filósofo fosse destinado a uma crítica aos pressupostos de Foucault a partir de Spinoza.

Esse mesmo alerta quanto a uma apropriação da perspectiva foucaultiana já havia sido feito, por exemplo, em Semântica e discurso:

Em sua Arqueologia do saber que, por muitos aspectos, apresenta um extraordinário interesse para a teoria do discurso, M. Foucault "retrocede" sobre o que ele mesmo avança, volta à sociologia das instituições e dos papéis, por não reconhecer a existência da luta (ideológica) de classes. (PÊCHEUX, 1988, p. 254)

A análise testemunhal, como dissemos acima, pode ser pertinente, mas com os devidos cuidados de inserir as falas dos sujeitos nas suas efetivas condições de produção.

Considerando-se esses elementos epistemológicos e históricos, trata-se de um equívoco a afirmação de que o conceito de FD da AD francesa vem dos trabalhos de Michel Foucault. Ou ainda pior, que o conceito de FD de Pêcheux é uma releitura do conceito de Foucault. Em nenhum trabalho de Pêcheux se encontra afirmação semelhante; mas, contrariamente, o autor diz:

Apoiando-nos em grande número de observações contidas no que chamamos de "os clássicos do marxismo", nós sustentaremos a ideia de que as formações ideológicas assim definidas comportam necessariamente, como um de seus componentes, uma ou várias formações discursivas interligadas [...]. (PÊCHEUX, 2011, p. 73)

Consideramos correto falar que, em sua história, a AD francesa buscou uma articulação com a perspectiva de Foucault, não apenas da fase arqueológica, mas também da genealógica, e que essa articulação recaiu sobretudo nos conceitos de FD de Pêcheux e de Foucault. Essa afirmação, sim, é condizente com os fatos históricos.

\section{CONSIDERAÇÕES FINAIS}

Como dissemos neste ensaio, a perspectiva mais pertinente para se compreender o conceito de FD da AD francesa (incluindo nessa história não somente a questão de sua paternidade, mas principalmente a de sua evolução) parece ser mesmo a epistemológica.

Quando adotada, permite que se comprove que o conceito de Pêcheux é exclusivo dele, e não uma mera transposição ou releitura de um conceito alheio - o conceito de Pêcheux, conforme demonstramos acima, foi elaborado de forma independente das reflexões de Foucault, mas de forma dependente das reflexões de Althusser, principalmente, e dos clássicos do marxismo; e também de Saussure e de Lacan; permite, ainda, inserir o conceito na sua rede conceitual e na sua problemática; permite, finalmente, compreender o processo de sua formação, retificação e deformação. 
ALTHUSSER, L. Aparelhos Ideológicos de Estado. Posições 2. Rio de Janeiro: Graal, 1980a. p. 47-101.

AUTHIER-REVUZ, J. Entre a transparência e a opacidade: um estudo enunciativo do sentido. Porto Alegre: EDPUCRS, 2004. p. 11-80.

BARONAS, R. Ainda sobre a noção-conceito de formação discursiva em Pêcheux e em Foucault. In: (Org.). Análise do Discurso: apontamentos para uma história da noção-conceito de formação discursiva. São Carlos: Pedro e João Editores, 2007, p. 169-181.

BRANDÃO, H. N. Introdução à análise do discurso. 7. ed. Campinas: Editora da UNICAMP, 2004.

CANGUILHEM, G. Études d'histoire et de philosophie des sciences. 7. ed. Paris: Vrin, 2002.

COURTINE, J.-J. Análise do discurso político: o discurso comunista endereçado aos cristãos. São Carlos: EDUFSCAR, 2009.

DELEUZE, G.; GUATTARI, F. O que é a Filosofia? Rio de Janeiro: Editora 34, 1992.

FOUCAULT, M. A arqueologia do saber. 2. ed. Rio de Janeiro: Forense-Universitária, 1986.

GARDIN, B. Discours patronal et discours syndical. Langages, Paris, n. 41, p. 13-46, 1976. Disponível em: <http://www.persee.fr/web/revues/home/prescript/article/lgge_0458-726x_1976_num_10_41_2302>. Acesso em: 14 jul. 2010.

GUILHAUMOU, J. Os historiadores do discurso e a noção-conceito de formação discursiva: narrativa de uma transvaliação imanente. In: BARONAS, R. (Org.). Análise do Discurso: apontamentos para uma história da noção-conceito de formação discursiva. São Carlos: Pedro e João Editores, 2007. p. 105-118.

HAROCHE, C.; HENRY, P.; PÊCHEUX, M. [1971]. A Semântica e o corte saussuriano: língua, linguagem, discurso. In: BARONAS, R. L. (Org.). Análise do Discurso: apontamentos para uma história da noção-conceito de formação discursiva. São Carlos: Pedro e João Editores, 2007, p. 13-32.

MACHADO, R. Ciência e Saber: a trajetória da arqueologia de Michel Foucault. 2. ed. Rio de Janeiro: Graal, 1988.

MACHEREY, P. A filosofia da ciência de Georges Canguilhem: epistemologia e história das ciências. In: CANGUILHEM, G. O normal e o patológico. 3. ed. Rio de Janeiro: Forense Universitária, 1990. p. 271 307.

MARCELLESI, J.-B. Analyse de discours à entrée lexicale (application à un corpus de 1924-1925). Langages, Paris, n. 41, p. 79-124, 1976. Disponível em:

<http://www.persee.fr/web/revues/home/prescript/article/lgge_0458-726x_1976_num_10_41_2304>. Acesso em: 22 maio 2010.

MAINGUENEAU, D.; CHARAUDEAU, P. Dicionário de Análise do discurso. São Paulo: Contexto, 2004.

MALDIDIER, D. A inquietação do discurso: reler Michel Pêcheux hoje. Campinas: Pontes, 2003.

NARZETTI, C. O percurso das ideias do Círculo de Bakhtin na Análise do discurso francesa. 2012. 262 f. Tese (Doutorado em Linguística e Língua Portuguesa) - Faculdade de Ciências e Letras, Universidade Estadual Paulista, Araraquara, 2012.

As linhas de Análise do Discurso na França nos anos 60-70. RevLet - Revista Virtual de Letras, v. 2, n. 2, p. 51-70, 2010. Disponível em: 〈http://www.revlet.com.br/artigos/52.pdf>.

NORMAND, C. De quelques notions fondamentales (sur un enseignement d'initiation à la linguistique). Langue Française, Paris, n. 14, p. 32-44, 1972. Disponível em: <http://www.persee.fr/doc/lfr_00238368_1972_num_14_1_5596>.Acesso em: 10 dez. 2016.

PÊCHEUX, M. [1983]. A análise de discurso: três épocas. In: GADET, Françoise; HAK, Tony (Org.) Por uma análise automática do discurso: uma introdução à obra de Michel Pêcheux. 3. ed. Campinas: Editora da Unicamp, 1997. p. 311-319.

[1981]. O estranho espelho da Análise do discurso. In: COURTINE, J.-J. Análise do discurso político: o discurso comunista endereçado aos cristãos. São Carlos: EDUFSCAR, 2009. p. 21-26.

[1977]. Remontons de Foucault à Spinoza. In: MALDIDIER, Denise. L' inquiétude du discours. Paris: Cendres, 1990. p. 245-260. 1988.

[1975]. Semântica e discurso: uma crítica à afirmação do óbvio. Campinas: Ed. da Unicamp, 
; FUCHS, C. [1975]. A propósito da Análise Automática do Discurso: atualização e perspectivas. In: GADET, F.; HAK, Tony (Org.). Por uma análise automática do discurso: uma introdução à obra de Michel Pêcheux. 2. ed. Campinas: Editora da Unicamp, 1997. p. 163-252.

SANTOS, J. V. dos. Foucault na formação discursiva da análise do discurso: um autor, um conceito, uma positividade. 2015. 162 f. Tese (Doutorado em Linguística) - Universidade Estadual de Campinas, Instituto de Estudos da Linguagem, Campinas, 2015.

Recebido em: 18/09/17. Aprovado em: 05/05/18

Title: For an epistemological history of the discursive formation concept

Author: Claudiana Narzetti

Abstract: This essay aims to resume some historical and epistemological issues related to the discursive formation concept developed by Michel Pêcheux in the heart of the French discourse analysis. It is a key concept of discourse theory that, paradoxically, became a source of misunderstandings, hurried assimilations and even proposals for abandonment. One resumes this topic as it was not exhaustively explored in the several current researches. The concept's epistemological issues are central in this essay and, based on historical data, they aim to clarify: the theoretical paradigm from which the concept was developed; its conceptual and permanent core; its changes (corrections, refinements and increases); the specificity of the concept developed by Michel Pêcheux and its demarcation of the homonym concept by Michel Foucault. The arguments and the conclusions achieved reveal, as such, some misunderstandings still existing today in the history of the French discourse Analysis.

Keywords: Discourse analysis. Discursive formation. Michel Pêcheux. Epistemology.

Título: Para una historia epistemológica del concepto de formación discursiva

Autor: Claudiana Narzetti

Resumen: Este ensayo tiene el objetivo de retomar algunas cuestiones históricas y epistemológicas relativas al concepto de formación discursiva, elaborado por Michel Pêcheux, en el seno del Análisis del discurso francés. Es un concepto central de la teoría del discurso, que paradójicamente, se ha tornado blanco de malentendidos, asimilaciones apresadas, y mismo propuestas de deserción. La retoma del tema se sostiene en la asunción de que él no fue exhaustivamente explorado en los trabajos existentes. Las cuestiones epistemológicas relacionadas al concepto son centrales en este ensayo, y sostenidas en datos históricos buscan aclarar: el paradigma teórico desde lo cual el concepto fue elaborado; su núcleo conceptual y permanente; sus cambios (rectificaciones, refinamientos y ampliaciones); la especificidad del concepto elaborado por Michel Pêcheux y su demarcación en relación al concepto homónimo de Michel Foucault. Los argumentos y las conclusiones obtenidas revelan algunos malentendidos que aún hoy permanecen en la historia del Análisis del discurso frances.

Palabras clave: Análisis del discurso. Formación discursiva. Michel Pêcheux. Epistemología.

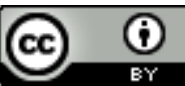

Este texto está licenciado com uma Licença Creative Commons Atribuição 4.0 Internacional. 